\title{
Metodologia da problematização e interdisciplinaridade: uma proposta para o ensino online
}

\author{
Methodology of problematization and interdisciplinarity: a proposal for \\ online teaching
}

\section{Metodología de la problematización y la interdisciplinariedad: una propuesta para la enseñanza online}

Andreza de Oliveira de Carvalho (andrezaoc@id.uff.br)

Doutoranda em Ciências, Tecnologias e Inclusão. Universidade Federal Fluminense - UFF.

Juliana Mendes da Silva (mendes_juliana@id.uff.br)

Doutoranda em Ciências, Tecnologias e Inclusão. Universidade Federal Fluminense - UFF.

Flavia Varriol de Freitas (flaviavarriol@id.uff.br)

Doutoranda em Ciências, Tecnologias e Inclusão. Universidade Federal Fluminense - UFF.

Gabriela dos Santos Leite Boechat (gabrielaboechat@id.uff.br)

Doutoranda em Ciências, Tecnologias e Inclusão. Universidade Federal Fluminense - UFF.

Edicléa Mascarenhas Fernandes (professoraediclea.uerj@gmail.com)

Professora no Departamento de Educação. Universidade Estadual do Rio de Janeiro - UERJ.

Gerlinde Agate Platais Brasil Teixeira (gerlinde_teixeira@id.uff.br)

Professora no Departamento de Imunologia. Universidade Federal Fluminense - UFF.

Resumo: O presente trabalho apresenta uma proposta para o ensino online que utiliza a metodologia da problematização enfatizando a interdisciplinaridade, para um público-alvo composto por alunos do terceiro ano do Ensino Médio. Tendo por objetivo ampliar o conhecimento sobre o consumo de produtos advindos da agropecuária e seus impactos. Foram consideradas as diferentes condições de ensino em decorrência da pandemia da COVID-19 que fez com que as instituições de ensino priorizassem atividades online. A abordagem metodológica utilizada foi a da problematização, através do método do Arco de Charles Maguerez. Buscamos, nos conceitos da interdisciplinaridade e ensino online, a possibilidade de superar a fragmentação do ensino que acontece mesmo diante de contextos habituais. As atividades propostas, buscaram promover o diálogo entre as disciplinas do currículo e a realidade da comunidade escolar com o auxílio de recursos digitais e a interação em ambientes virtuais. Embora sejam atividades propostas para o Ensino Médio, consideramos que também são passíveis de aplicação aos demais níveis de ensino.

Palavras-chave: metodologia por problematização; interdisciplinaridade; ensino online. 


\begin{abstract}
The present work presents a proposal for online teaching that uses the problematization methodology, emphasizing interdisciplinarity, for a target audience composed of grade 12 high school students. The aim is to increase knowledge on the consumption of animal derived products and its impacts. Different teaching conditions were considered due to the COVID-19 pandemic, which made educational institutions prioritize online activities. The methodological approach was that of Charles Maguerez's Arch problematization method. We seek, in the concepts of interdisciplinarity and online teaching, the possibility of overcoming the fragmentation of teaching that happens even in the face-to-face contexts. The activities proposed sought to promote dialogue between the subject matters and the reality of the school community with the help of digital resources and interaction in virtual environments. Although the activities are proposed for high school education, we consider that they can also be applied to other levels of education.
\end{abstract}

Keywords: problematization methodology; interdisciplinarity; online teaching.

Resumen: El presente trabajo presenta una propuesta de enseñanza en línea que utiliza la metodología de problematización, enfatizando la interdisciplinariedad, para un público objetivo compuesto por estudiantes de tercer año de secundaria, que tiene como objetivo aumentar el conocimiento sobre el consumo de productos pecuarios y sus impactos. Se consideraron diferentes condiciones de enseñanza como resultado de la pandemia COVID-19, que hizo que las instituciones educativas priorizaran las actividades en línea. El enfoque metodológico utilizado fue el de la problematización, a través del método Arco de Charles Maguerez. Buscamos, en los conceptos de interdisciplinariedad y enseñanza online, la posibilidad de superar la fragmentación de la enseñanza que ocurre incluso en los contextos habituales. Las actividades propuestas buscaron promover el diálogo entre las materias curriculares y la realidad de la comunidad escolar con la ayuda de los recursos digitales y la interacción en entornos virtuales. Si bien las actividades están propuestas para la educación secundaria, consideramos que también se pueden aplicar a otros niveles educativos.

Palabras-clave: metodología por problematización; interdisciplinariedad; enseñanza en línea.

\title{
1. INTRODUÇÃO
}

O ano de 2020 marca uma nova fase no processo de uso das Tecnologias Digitais da Informação e Comunicação (TDIC) na educação, principalmente no ensino básico. No Brasil, por exemplo, segundo dados do Censo Escolar de 2019, havia 47,9 milhões de alunos matriculados na educação básica (INEP, 2019). Esse número contribui para vislumbrar a quantidade de jovens que, diante da pandemia do novo Corona vírus (Covid-19), permanecem em casa, cumprindo determinações sanitárias de isolamento social e, portanto, com aulas presenciais suspensas. Diante dessa situação, o Ministério da Educação (MEC) homologou o parecer CNE/CP número 05 de 2020, que estabelece as diretrizes para o ensino durante a pandemia (BRASIL, 2020). Nele, há a indicação da validade das aulas na modalidade Educação

Recebido em: 05/1 1/2021

Aceite em: 26/08/2021 
a Distância (EaD) a partir do ensino fundamental para fins de cumprimento de carga horária obrigatória.

As instituições de ensino, se adaptaram, e estão utilizando de diversas formas as plataformas digitais como Ambientes Virtuais de Aprendizagem (AVA) para darem continuidade às atividades letivas. Em um extremo temos instituições que aproveitaram suas infraestruturas de $\mathrm{EaD}$ e no outro temos instituições que deixaram seus professores realizando a simples transposição do presencial para o virtual. Nesse contexto, é importante destacar que há diferenças entre a $\mathrm{EaD}$ e o que está sendo denominado de ensino remoto ou digital emergencial.

O ensino remoto emergencial surge, então, da necessidade de continuidade das atividades letivas diante da suspensão de aulas presenciais decorrente da pandemia de COVID-19. Ele se assemelha à $\mathrm{EaD}$ apenas na necessidade de uma educação mediada pelas TDIC devido à distância temporal e geográfica entre professores e alunos. Isso porque, o objetivo não é recriar uma nova modalidade de ensino, mas oferecer acesso aos conteúdos e aulas, muitas vezes conforme os da educação presencial, de maneira a minimizar os efeitos da suspensão das atividades letivas presenciais. $\mathrm{O}$ termo remoto diz respeito apenas à mudança do espaço das aulas, que outrora era presencial e agora, temporariamente, é digital e "é emergencial porque o planejamento pedagógico para o ano letivo de 2020 foi subitamente engavetado" (FARIA et al., 2020, p. 2).

Não pretendemos nos aprofundar nas discussões acerca das diferenças entre EaD e ensino remoto, contudo, cabe ressaltar que utilizar os AVAs para apenas postar textos em PDF, ou fazer apresentações de slides é subutilizar a potencialidade do uso das TDIC nesse processo. Nesse sentido, há mais de uma década, Santos (2009) já defendia o conceito chamado de "educação online", a qual define como "[...] o conjunto de ações de ensino-aprendizagem ou atos de currículo mediados por interfaces digitais que potencializam práticas comunicacionais interativas e hipertextuais [...]" (SANTOS, 2009, p.5663). Seguindo esse caminho, hoje, a autora, indica que na educação online é preciso que os conhecimentos sejam produzidos de forma colaborativa nas interfaces da comunicação síncrona (online) e assíncrona (offline) através de chats, fóruns, web conferências e wikis, por exemplo (SANTOS, 2020). Concordamos com Joyce, Moreira e Rocha (2020, p. 8) que "a educação online seria um subconjunto da $\mathrm{EaD}$, permeada pela colaboração proposta pela Web 2.0 e suas interfaces digitais, as quais permitem uma interação maior, praticamente inexistente no primeiro modelo". 
Sendo assim, neste artigo, ao pensarmos no uso das tecnologias digitais como recurso para mediação do processo de aprendizagem em tempos de pandemia, entendemos que mais do que definir o AVA ou qualquer outra ferramenta digital, é mais importante definirmos a metodologia a ser utilizada. É através da metodologia que nos distanciaremos do ensino remoto, enquanto nos aproximamos da educação online.

Documentos oficiais do MEC, como os Parâmetros Curriculares Nacionais, já indicavam a importância da interdisciplinaridade para um ensino crítico e contextualizado (BRASIL, 2000). Moura, Sousa e Carneiro (2018) entendem que o papel do professor seja de promover uma aprendizagem com significado dos conteúdos curriculares associando-os com o cotidiano social do aluno. A organização atual, por áreas de conhecimento, na Base Nacional Comum Curricular (BNCC) para o Ensino Médio (EM), reforça a interação entre alunos, professores e áreas do conhecimento, portanto, a interdisciplinaridade (BRASIL, 2018). Desta forma, Reis et al. (2021) reforça que a BNCC orienta sobre a condução da atuação docente, contudo, o ensino desses diferentes conhecimentos é regido pela prática desse educador, o qual possui autonomia para organizar e definir as melhores estratégias e metodologias para executar o seu trabalho.

Ao buscarmos uma metodologia que proporciona o trabalho colaborativo, necessário à educação online, encontramos a Metodologia da Problematização (MP), baseada no Arco de Charles Maguerez (BERBEL, 2014). Esta se aplica às situações nas quais os temas estejam relacionados com a vida em sociedade. Assim, o objetivo deste trabalho é apresentar uma proposta didática para o $3^{\circ}$ do Ensino Médio com base na MP, que leva em consideração as competências e habilidades contidas na BNCC. Esta proposta tem ainda como referência os princípios da educação online e da interdisciplinaridade no contexto da suspensão das aulas presenciais devido a pandemia de Covid-19 e a necessidade de se usar AVA.

\section{A METODOLOGIA DA PROBLEMATIZAÇÃO POR MAGUEREZ}

O Arco de Charles Maguerez, baseado nos princípios da Pedagogia Problematizadora, se inspirou em ideias críticas da educação, com uma perspectiva transformadora da sociedade. A MP versa sobre temas "polêmicos", que possam ser analisados por diferentes ângulos (histórico, legal, ético, econômico, social, ambiental etc.) e "[...] tem a característica de partir da realidade concreta onde a temática e o estudo possam ter elementos vivos para fornecer ao estudante [...]" (BERBEL, 2014, p. 65). O método é composto por cinco etapas/momentos (BERBEL, 1998 e 2014), cada uma destas etapas será descrita a seguir.

Recebido em: 05/11/2021

Aceite em: 26/08/202 1 
Observação da realidade ( $1^{\text {a }}$ etapa) - os alunos serão orientados a observar com atenção e a registar de forma sistemática o que perceberem sobre a temática em questão. Berbel (1998) orienta que os docentes podem dirigir essa observação através de questões gerais para que seja mantido o foco, sem fuga do tema. Esse olhar minucioso permitirá que os alunos identifiquem dificuldades, carências, discrepâncias etc. que serão transformadas em problemas e problematizadas. Sugere, ainda, que o grupo escolha um problema para todos estudarem ou vários problemas por grupos menores. Nessa primeira etapa o docente pode utilizar diversas estratégias (documentários, filmes, reportagens/notícias, discussão em grupo, LIVE com especialistas da temática etc.) que possibilitem a aproximação dos alunos à realidade. Ao final, recomenda-se que o problema discutido pelo grupo seja redigido.

Pontos-chave ( $2^{\text {a }}$ etapa), os alunos serão conduzidos a refletir inicialmente sobre as possíveis causas da existência do problema, definido na etapa anterior. Essa condução pode ser realizada através de questionamentos pelos docentes. Nesse processo reflexivo, os alunos são estimulados a elaborar os pontos importantes a serem estudados para que o problema possa ser compreendido mais profundamente e formas de intervir na realidade possam ser encontradas, a fim de solucioná-la ou mitigá-la. Os pontos-chave elaborados nortearão os tópicos serem estudados.

Teorização ( $3^{\text {a }}$ etapa) é o momento em que os alunos investigarão sobre o problema, buscarão informações que esclareçam os pontos-chave definidos. As fontes de informação poderão ser diversas: texto, artigo, notícias, entrevista, podcast, consulta com especialista, participação em palestras ou webinários, aplicação de questionário, exibição de documentários etc. O produto da coleta de informações deverá ser tratado, analisado e avaliado, em grupo, quanto às suas contribuições para resolver o problema.

Hipóteses de solução ( $4^{\mathrm{a}}$ etapa) consiste na elaboração de possíveis alternativas para solucionar o problema identificado, de forma crítica e criativa, contrapondo teoria e realidade. Berbel (1998) sinaliza questionamentos que devem permear essa etapa, tais como: O que precisa ocorrer para que o problema seja solucionado? O que precisa ser fornecido? O que pode realmente ser feito?

Aplicação à realidade ( $5^{\mathrm{a}}$ etapa), corresponde a prática, onde os alunos serão conduzidos à construir novos conhecimentos que possibilitem transformar a realidade observada e o compromisso deles com o meio que estão inseridos. 
Essa metodologia cumpre dois propósitos: desenvolver o aluno/ser humano e contribuir, de alguma forma, para transformar a realidade. O intuito não é resolver os problemas existentes no mundo ou do lugar que os indivíduos estejam inseridos, e sim o convite é exercitar (pequenas) intervenções em algumas realidades, através de ações reflexivas, analíticas e dialéticas (BERBEL, 2014). A MP, reforça a interação entre alunos, professores e áreas do conhecimento, portanto, a interdisciplinaridade bem como o protagonismo do aluno, uma questão que aflorou durante a pandemia.

\section{METODOLOGIA DA PESQUISA}

Ao realizarmos um levantamento bibliográfico no portal de periódicos da CAPES, no final do primeiro semestre de 2020, a fim de identificarmos os trabalhos publicados que utilizaram a metodologia da problematização no Ensino Médio, obtivemos como resultado da busca 129 periódicos revisados por pares, nos últimos 20 anos. Contudo, em nenhum deles foi abordado o tema deste trabalho, sobre "Consumo alimentar e as pandemias". Sendo assim, apresentaremos neste tópico as justificativas que nos levaram a considerar os princípios da educação online e da interdisciplinaridade e a optar pela Metodologia da Problematização para elaborar, organizar e ordenar as atividades de nossa proposta didática para este tema.

Escolhemos fazer uso dos pressupostos da educação online, entendida como um conjunto de ações de ensino e de aprendizagem, mediadas por AVA, que permitem o fortalecimento de práticas comunicacionais interativas e hipertextuais. Para que isso ocorra, é preciso ter uma apropriação adequada do AVA escolhido que não pode, por exemplo, ser usado apenas como repositório de materiais impressos.

\footnotetext{
Além da auto-aprendizagem, as interfaces dos AVAs permitem a interatividade e a aprendizagem colaborativa. O cursista aprende com o material didático e na dialógica com outros sujeitos envolvidos - professores, tutores e outros cursistas, através de processos de comunicação síncronos e assíncronos (SANTOS, 2009, p. 5665).
}

Tomando como referência as concepções da educação online e as habilidades e competências da BNCC do EM, elaboramos uma proposta didática a ser desenvolvida em AVA com o uso de recursos tecnológicos complementares que julgamos necessários à aplicação de atividades em uma perspectiva interdisciplinar. 
Destacamos que o entendimento sobre interdisciplinaridade adotado neste trabalho parte, principalmente, das proposições de Severino (2008) e de Fazenda (2008 e 2012). Conforme Severino (2008), as práticas interdisciplinares precisam sempre considerar a articulação do todo com as partes bem como a articulação dos meios com os fins. Para construir o saber é importante a prática da pesquisa ativa, ou seja, agir é fundamental para aprender. Como o saber solto fica esquematizado, petrificado, volatilizado, é preciso sempre o construir pela força da intencionalidade.

Fazenda (2008) entende que a interdisciplinaridade escolar tem como objetivo contribuir para o processo de aprendizagem levando em consideração a integração dos saberes dos alunos. Embora não seja uma proposta nova, vem se revelando como uma boa ação pedagógica. Dessa forma, salientamos a importância da interdisciplinaridade nas escolas e justificamos, assim, nossa escolha por seguir essa orientação.

\section{DESCRIÇÃO DA PROPOSTA}

\subsection{TEMA E JUSTIFICATIVA}

Quando se opta por trabalhar com a MP, o caminho a ser percorrido parte da realidade social observada. Esta provoca questionamentos que permitem que se forme o quadro conceitual, que leva a análise teórica e proposições de solução do problema. O ano de 2020 foi marcado pela pandemia de Covid-19, assim a proposta empírica e interdisciplinar tem como tema a relação entre o consumo alimentar e as pandemias baseado no alerta que a comunidade científica tem feito sobre a relação entre o consumo de proteína animal e o surgimento e ressurgimento de doenças com potencialidade pandêmica.

Davis (2006) fez um alerta para a inevitabilidade, ainda no século XXI, de uma nova pandemia no estilo da gripe espanhola, de 1918, que matou cerca de 20 milhões de pessoas ao redor do mundo. Segundo o autor, a pecuária intensiva, usada por grandes empresas para criação de frangos e suínos, assim como a sua separação da agricultura, vêm criando as condições de um "cadinho pandêmico". Este autor aponta ainda que o aumento de contato dos humanos com animais selvagens devido aos desmatamentos são condições para que haja novas contaminações e novas doenças.

O livro Pandemias, saúde global e escolhas pessoais (2020) dos pesquisadores brasileiros Cynthia Paim e Wladimir Alonsoz mostra como surtos de doenças, nas últimas décadas, como Recebido em: 05/11/2021

Aceite em: 26/08/2021 
H1N1 e Covid-19, por exemplo, têm alguma relação com a forma contemporânea de criação e consumo de proteína animal. Santos (2006) em documento oficial da Embrapa mostra que os sistemas de criação pecuária intensiva contribuem para a disseminação de patógenos, uma vez que a transmissão de um animal para o outro é facilitada quando eles são encerrados em locais de alta densidade.

Estes aspectos, tem sido objeto de muita controvérsia, científica, bem como política, intelectual, econômica, ambiental, sanitária e mesmo cultural. A título de ilustração, temos a tematização desta questão, em filmes como Okja e documentários como Cowspiracy. Enfim, o alcance da temática e sua compatibilidade com o curso dos acontecimentos contemporâneos, justificam uma proposta interdisciplinar das diversas dimensões e aspectos das relações entre consumo alimentar e disseminação de doenças.

\subsection{PÚBLICO-ALVO E DELIMITAÇÃO DO CONTEÚDO}

Sugerimos como público-alvo alunos do $3^{\circ}$ ano do Ensino Médio, por terem maior maturidade acadêmica. Contudo, esta proposta, com suas devidas adequações, também cabe para os demais anos do Ensino Básico. O conteúdo será delimitado por áreas de conhecimento, conforme indicado pela BNCC. Para cada área são indicadas possibilidades de abordagem disciplinares que entendemos como adequadas para o desenvolvimento das habilidades e competências listadas na BNCC (Quadro 1).

\subsection{AVALIAÇÃO}

Seguindo o conceito de avaliação mediadora, desenvolvido por Hoffman (2011), sugerimos uma proposta de avaliação que toma o texto dos alunos como o ponto de partida e de chegada do processo de ensino e de aprendizagem, conforme defendido, ainda, por Geraldi (2013). A ideia é propor aos alunos a produção de um texto dissertativo-argumentativo sobre a relação entre consumo alimentar e pandemias no início da sequência didática e, ao final dela, solicitar a refacção do texto. Entendemos que as produções dos alunos devem ser avaliadas de forma a dar, inicialmente, subsídios que norteiem os professores quanto às atividades que podem ser desenvolvidas, considerando aquilo que os alunos já sabem ou não em relação ao tema e aos aspectos linguísticos. Já a avaliação da produção final, deve revelar aquilo que efetivamente se aprendeu, além de promover a aprendizagem através da refacção dos textos pelos alunos a partir do feedback dos professores.

\subsection{SEQUÊNCIA DIDÁTICA}

Recebido em: 05/11/2021

Aceite em: 26/08/2021 
A proposta elaborada segue a metodologia da problematização, contendo as cinco etapas do Arco de Maguerez (BERBEL, 1998 e 2014).

O tempo sugerido para cada parte da sequência está indicado no Quadro 2, assim como, a descrição do encontro, recursos de apoio, atividades a serem desenvolvidas pelos alunos e outras questões que julgamos pertinentes apresentar.

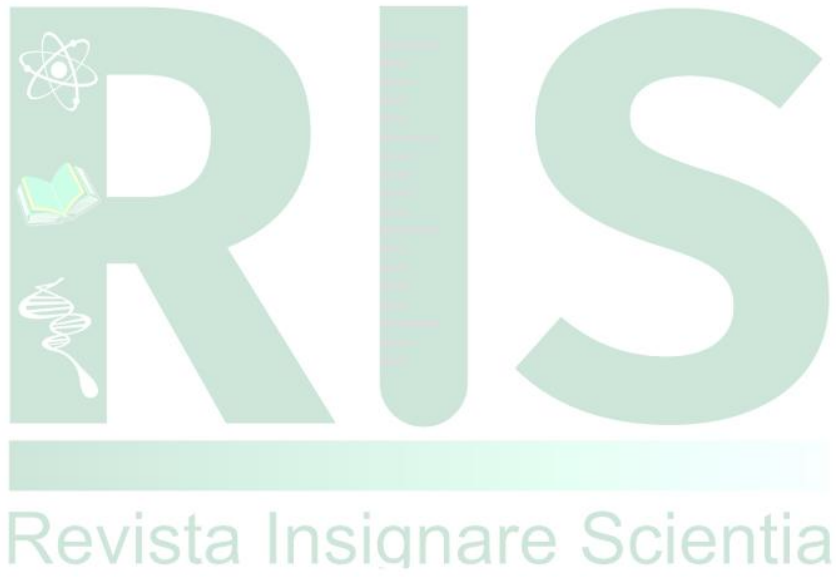


Quadro 1 - Áreas do conhecimento e delimitação de conteúdos

\begin{tabular}{|c|c|c|}
\hline $\begin{array}{l}\text { ÁREA DO } \\
\text { CONHECIMENTO }\end{array}$ & ASSUNTOS EM RELAÇÃO AO TEMA & CONTEÚDO ESPECÍFICO A SER TRABALHADO \\
\hline \multirow{2}{*}{$\begin{array}{l}\text { Ciências da } \\
\text { Linguagem e Suas } \\
\text { Tecnologias }\end{array}$} & $\begin{array}{l}\text { Ampliação lexical em relação ao tema e compreensão } \\
\text { morfológica }\end{array}$ & $\begin{array}{l}\text { - Processo de formação de palavras como pandemia, endemia e epidemia. (Língua } \\
\text { portuguesa). } \\
\text { - Relações lexicais entre o inglês e o português. (Língua inglesa). }\end{array}$ \\
\hline & Interdiscursividade em textos informativos & $\begin{array}{l}\text { - Estudo da estrutura composicional, do estilo e do conteúdo temático de gêneros informativos } \\
\text { jornalísticos e científicos. (Língua Portuguesa). }\end{array}$ \\
\hline \multirow{2}{*}{$\begin{array}{l}\text { Ciências Humanas e } \\
\text { Sociais Aplicadas }\end{array}$} & $\begin{array}{l}\text { As relações das sociedades com a natureza e seus } \\
\text { impactos econômicos e socioambientais. }\end{array}$ & $\begin{array}{l}\text { - Produção do espaço agropecuário mundial; sistemas agropecuários desde o período neolítico } \\
\text { até o atual; Favorecimento de grandes empresas em detrimento dos pequenos produtores no } \\
\text { contexto de produção capitalista (Geografia). }\end{array}$ \\
\hline & As grandes epidemias ao longo da história. & $\begin{array}{l}\text { - A história das doenças; } \\
\text { - Comparação entre a pandemia de Covid-19 e pandemias anteriores, como Peste Bubônica e } \\
\text { Gripe espanhola (História). }\end{array}$ \\
\hline \multirow{2}{*}{$\begin{array}{l}\text { Matemática e suas } \\
\text { tecnologias }\end{array}$} & $\begin{array}{l}\text { Notícias divulgadas sobre situações econômicas e } \\
\text { sociais que envolvem a variação de duas grandezas. }\end{array}$ & - Análise de gráficos das funções representadas e das taxas de variação (Matemática). \\
\hline & $\begin{array}{l}\text { Relação entre a densidade de animais em um mesmo } \\
\text { ambiente e a propagação de doenças entre eles. }\end{array}$ & - Funções matemáticas (Matemática). \\
\hline \multirow{3}{*}{$\begin{array}{l}\text { Ciências da } \\
\text { Natureza e suas } \\
\text { tecnologias }\end{array}$} & $\begin{array}{l}\text { Relação da disseminação de doenças com a cultura } \\
\text { alimentar contemporânea. }\end{array}$ & $\begin{array}{l}\text { - Zoonoses (Biologia). } \\
\text { - Estrutura de Macromoléculas e interação (Química). }\end{array}$ \\
\hline & $\begin{array}{l}\text { Ciclagem de elementos químicos no solo, atmosfera } \\
\text { e seres vivos, interpretando os efeitos de fenômenos } \\
\text { naturais e da interferência humana. }\end{array}$ & $\begin{array}{l}\text { - Contaminação de lençóis freáticos; } \\
\text { - Monocultura; Empobrecimento do solo; } \\
\text { - Uso excessivo de recursos naturais (Biologia). }\end{array}$ \\
\hline & Biotecnologia & $\begin{array}{l}\text { - Composição de vacinas e suas funções; Composição de álcool Gel. (Química). } \\
\text { - Produção de testes para Covid-19 e prevenção de pandemias (Biologia). } \\
\text { - Medidas de higiene pessoal (Biologia). }\end{array}$ \\
\hline
\end{tabular}

Recebido em: 05/11/2021

Aceite em: 26/08/2021 
ISSN: 2595- 4520

Quadro 2 - Planejamento da Sequência Didática

\begin{tabular}{|c|c|c|c|c|c|c|}
\hline \multicolumn{3}{|c|}{ Descrição do encontro } & \multirow{2}{*}{$\begin{array}{l}\text { Recursos } \\
\text { de apoio }\end{array}$} & \multicolumn{2}{|c|}{ Responsabilidade } & \multirow{2}{*}{$\begin{array}{c}\text { Observacões: } \\
\begin{array}{c}\text { Gravar e disponibilizar } \\
\text { no AVA }\end{array} \\
\end{array}$} \\
\hline Sequência & Tipo & Duração & & do professor / tutor & dos alunos & \\
\hline \multirow{4}{*}{ Apresentação } & \multirow{4}{*}{ Síncrono } & $45 \mathrm{~min}$ & Power Point & $\begin{array}{l}\text { - Apresentação da atividade, potencialidades da } \\
\text { metodologia de problematização e avaliações } \\
\text { - Discutir o conceito e significado das palavras } \\
\text { endemia, epidemia e pandemia. } \\
\text { - Esclarecimento de possíveis dúvidas }\end{array}$ & \multirow{4}{*}{$\begin{array}{l}\text { - Participar } \\
\text { - Apresentar dúvidas } \\
\text { - Fornecer os números de } \\
\text { telefone } \\
\text { - Preencher o questionário } \\
\text { até, no máximo, } 48 \mathrm{~h} \text { antes } \\
\text { do próximo encontro. } \\
\text { - Assistir o vídeo para o } \\
\text { próximo encontro }\end{array}$} & \multirow{4}{*}{$\begin{array}{l}\text { - Sugestão para a } \\
\text { confecção do } \\
\text { questionário: pode } \\
\text { conter questões sobre } \\
\text { hábitos alimentares dos } \\
\text { alunos e das famílias, } \\
\text { meios de produção } \\
\text { sustentáveis e } \\
\text { industriais, doenças, } \\
\text { pandemias etc. } \\
\text { - Disponibilize o link do } \\
\text { vídeo no AVA. }\end{array}$} \\
\hline & & $15 \min$ & WhatsApp & - Formação de grupo no WhatsApp & & \\
\hline & & $15 \mathrm{~min}$ & $\begin{array}{l}\text { Questionário } \\
\text { Forms }\end{array}$ & $\begin{array}{l}\text { - Solicitar o preenchimento de questionário, } \\
\text { disponibilizado no AVA e por WhatsApp }\end{array}$ & & \\
\hline & & $15 \mathrm{~min}$ & & $\begin{array}{l}\text { - Solicitar que os alunos assistam ao vídeo “A } \\
\text { História das coisas” Disponível em: } \\
\text { https://www.youtube.com/watch?v=7qFiGMSn } \\
\text { Njw }\end{array}$ & & \\
\hline \multirow{4}{*}{$\begin{array}{l}\text { 1. }{ }^{\mathbf{a}} \text { etapa: } \\
\text { Problematização } \\
\text { e observação da } \\
\quad \text { realidade }\end{array}$} & \multirow{4}{*}{ Síncrono } & $10 \mathrm{~min}$ & Power Point & $\begin{array}{l}\text { - Apresentação, por compartilhamento de tela, } \\
\text { das respostas dos alunos sobre o questionário } \\
\text { disponibilizado no encontro anterior }\end{array}$ & \multirow{4}{*}{$\begin{array}{l}\text { - Tirar dúvidas que restaram } \\
\text { - Cada grupo deve apresentar } \\
\text { uma sintetize do que } \\
\text { observou e registrou. } \\
\text { - Redigir, individualmente, a } \\
\text { redação no modelo ENEM } \\
\text { - Observar atentamente e } \\
\text { registrar o que perceberem } \\
\text { sobre as relações de } \\
\text { consumo de produtos } \\
\text { agropecuários em casa. }\end{array}$} & \multirow{4}{*}{$\begin{array}{l}\text { - Definir ou sugerir se o } \\
\text { trabalho com os alunos } \\
\text { será num grupão ou em } \\
\text { grupos menores (de } 4 \\
\text { ou } 5 \text { alunos) para que } \\
\text { estudem problemas } \\
\text { distintos. } \\
\text { - Incluir em cada grupo } \\
\text { um professor, que terá } \\
\text { a função de mediador. } \\
\text { - Se preferir, utilize } \\
\text { outras plataformas para } \\
\text { a troca das mensagens. }\end{array}$} \\
\hline & & $40 \mathrm{~min}$ & Live & $\begin{array}{l}\text { - Discussão do vídeo disponibilizado } \\
\text { anteriormente e condução para o consumo de } \\
\text { produtos agropecuários } \\
\text { - Solicitar que os alunos redijam uma redação } \\
\text { Modelo ENEM }{ }^{1} \text { sobre a relação entre consumo } \\
\text { alimentar e pandemias. }\end{array}$ & & \\
\hline & & $30 \mathrm{~min}$ & $\begin{array}{l}\text { Voxvote ou } \\
\text { Infogram }\end{array}$ & $\begin{array}{l}\text { - Atividade em grupo: usar algum app de } \\
\text { feedback ou nuvem de palavras e ver qual tem } \\
\text { mais destaque }\end{array}$ & & \\
\hline & & $10 \mathrm{~min}$ & WhatsApp & $\begin{array}{l}\text { - Dividir os alunos em pequenos grupos ( } 4 / 5 \\
\text { alunos), criem grupos no WhatsApp para }\end{array}$ & & \\
\hline
\end{tabular}

${ }^{1}$ Disponibilizada através do link: https://docs.google.com/document/d/1M6IaXG7N1as_aQATFIVPVJs5QPTT6r5mGs9IFc1zuZo/edit?usp=sharing

Recebido em: 05/11/2021

Aceite em: 26/08/2021 
ISSN: 2595- 4520

\begin{tabular}{|c|c|c|c|c|c|c|}
\hline \multicolumn{3}{|c|}{ Descrição do encontro } & \multirow{2}{*}{$\begin{array}{l}\text { Recursos } \\
\text { de apoio } \\
\end{array}$} & \multicolumn{2}{|c|}{ Responsabilidade } & \multirow{2}{*}{$\begin{array}{c}\text { Observacões: } \\
\begin{array}{c}\text { Gravar e disponibilizar } \\
\text { no AVA }\end{array}\end{array}$} \\
\hline Sequência & Tipo & Duração & & do professor / tutor & dos alunos & \\
\hline & & & & $\begin{array}{l}\text { observação das relações de consumo de } \\
\text { produtos agropecuários em casa. }\end{array}$ & & \\
\hline \multirow{3}{*}{$\begin{array}{l}\text { Delimitação do } \\
\text { problema e } \\
\text { identificando os } \\
\text { pontos-chave }\end{array}$} & \multirow{3}{*}{ Síncrono } & $30 \mathrm{~min}$ & Power Point & $\begin{array}{l}\text { - Os professores mediadores devem orientar a } \\
\text { elencar os problemas e auxiliar na redação } \\
\text { sobre o problema escolhido por grupo. } \\
\text { - Sugestão de alguns problemas: }\end{array}$ & \multirow{3}{*}{\begin{tabular}{lrr} 
- Os grupos & \multicolumn{2}{c}{ deverão } \\
sistematizar o & que foi \\
observado por & eles e \\
transformar as observações \\
em problemas. \\
- Cada grupo & deverá \\
selecionar um relator para \\
apresentar o problema \\
escolhido pelo grupo. A \\
turma deverá escolher um \\
problema ou & vários \\
problemas, para & serem \\
trabalhados em & grupos \\
menores & \\
- A partir da & identificação \\
dos principais & aspectos \\
(pontos-chave) elencados, \\
os alunos serão orientados \\
a iniciar seus processos de \\
investigação.
\end{tabular}} & \multirow{3}{*}{ 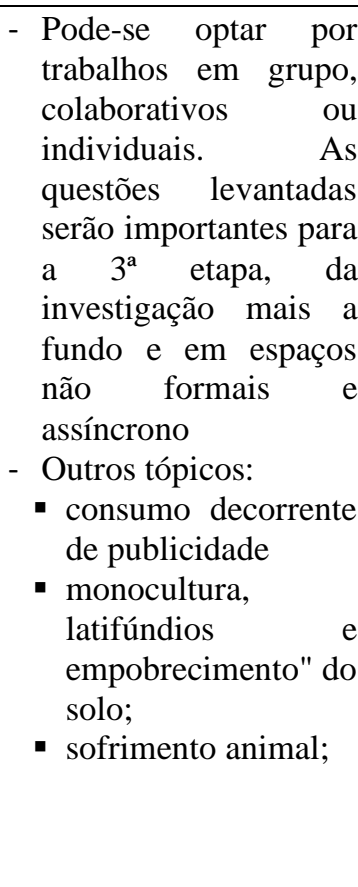 } \\
\hline & & $30 \mathrm{~min}$ & WhatsApp & $\begin{array}{l}\text { - desmatamento, invasão de áreas de proteção } \\
\text { ambiental; indígenas e / ou quilombolas; } \\
\text { - contaminação do solo e lençóis freáticos; } \\
\text { - zoonoses (pandemias, doenças novas, doenças } \\
\text { antigas reemergentes); } \\
\text { - favorecimento grandes empresas em } \\
\text { detrimento dos pequenos produtores. } \\
\text { - motivos de pandemias que já ocorreram. }\end{array}$ & & \\
\hline & & $\begin{array}{l}30 \mathrm{~min} \\
1 \mathrm{Sta}\end{array}$ & & $\begin{array}{l}\text { - Compreendendo o problema: os alunos serão } \\
\text { levados a refletir e elencar as variáveis } \\
\text { determinantes da situação sobre } \\
\text { - "como o consumo de carne está associado às } \\
\text { pandemias?", } \\
\text { - "como a criação dos animais impacta o meio } \\
\text { ambiente?" } \\
\text { - "como isso afeta os alunos e a sociedade?" }\end{array}$ & & \\
\hline$\frac{\mathbf{3}^{\mathbf{a}} \text { etapa: }}{\text { Teorização }}$ & $\begin{array}{l}\text { Tudo } \\
\text { Assíncrono } \\
\text { ou } \\
\text { parte } \\
\text { assíncrono } \\
\text { e parte } \\
\text { síncrono }\end{array}$ & $180 \mathrm{~min}$ & $\begin{array}{l}\text { Power Point } \\
\text { WhatsApp }\end{array}$ & $\begin{array}{l}\text { - Estimular que os alunos: } \\
\text { - apresentem fatos ou dados que foram } \\
\text { pesquisados para os demais alunos, através de } \\
\text { publicações no AVA, por exemplo; } \\
\text { - entrevistem alguém que seja diretamente } \\
\text { impactado; } \\
\text { - acessem vídeos ou séries ou blogs, } \\
\text { disponibilizados na internet; } \\
\text { - busquem iniciativas de proteção ambiental, } \\
\text { ONG's }\end{array}$ & $\begin{array}{l}\text { - Esse momento é entendido } \\
\text { como uma busca, de } \\
\text { informações que permitem } \\
\text { a compreensão do(s) } \\
\text { problema(s) } \\
\text { identificado(s) sobre o } \\
\text { consumo de produtos } \\
\text { agropecuários. }\end{array}$ & $\begin{array}{l}\text { - Recomendamos que } \\
\text { esse momento tenha a } \\
\text { duração de duas } \\
\text { semanas. } \\
\text { - Disponibilizar } \\
\text { materiais no AVA, na } \\
\text { forma de uma } \\
\text { "biblioteca". }\end{array}$ \\
\hline
\end{tabular}

Recebido em: 05/11/2021

Aceite em: 26/08/2021 


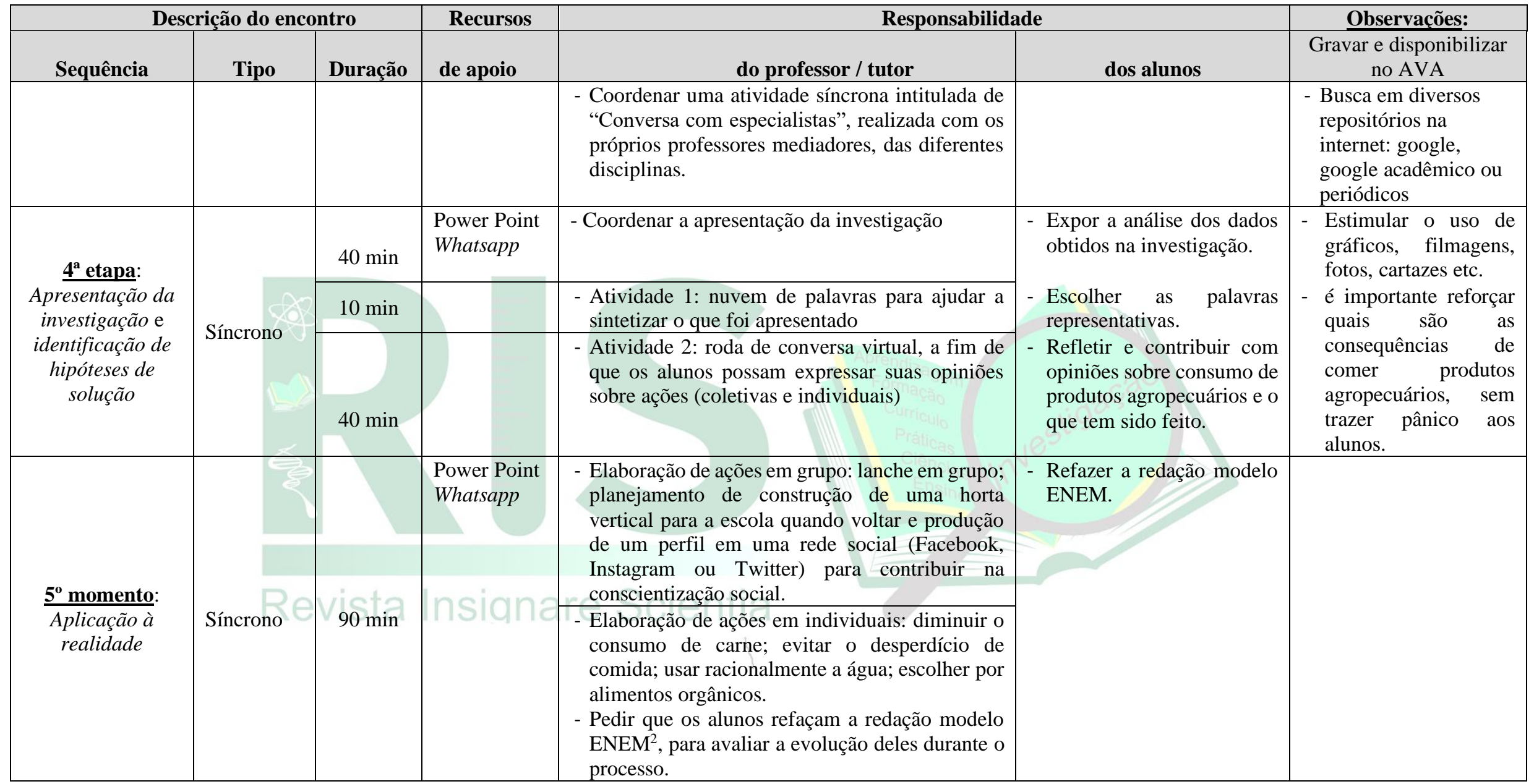

Fonte: Elaborado pelas autoras.

${ }^{2}$ Disponibilizado através do link: https://docs.google.com/document/d/1M6IaXG7N1as_aQATFIVPVJs5QPTT6r5mGs9IFc1zuZo/edit?usp=sharing Recebido em: 05/11/2021 


\section{CONSIDERAÇÕES FINAIS}

Em relação à aplicação desta sequência didática, espera-se que haja desenvolvimento da autonomia e protagonismo dos alunos, aprimoramento das habilidades de planejamento e resolução de problemas, aperfeiçoamento do trabalho em equipe, valorização da diversidade, e possíveis modificações práticas na vida, individual e social, dos alunos. Está nas nossas perspectivas a aplicação da estratégia proposta no contexto escolar onde cada autora trabalha.

Sobre o conteúdo temático abordado, espera-se que os alunos sejam capazes de compreender e analisar a relação da sociedade com a natureza e seus impactos econômicos, políticos, culturais e ambientais. Sejam capazes de a partir de uma situação-problema real propor soluções a nível local, regional ou mundial. Sejam capazes de aplicar novos conceitos sobre a relação entre o consumo alimentar contemporâneo e a propagação de doenças. E, por último, sejam capazes de se expressar verbalmente a fim de defender um posicionamento sobre a relação entre pandemias e modelo agropecuário atual.

Em relação à perspectiva interdisciplinar, espera-se que os professores e a equipe educacional como um todo percebam que a interdisciplinaridade significa realinhar a questão das disciplinas e suas relações contribuindo para um aprendizado significativo pelos alunos. Para isso, há necessidade de uma integração entre os professores para que discutam as dificuldades, os resultados e os materiais utilizados.

Em suma, com a temática sobre o consumo alimentar e o surgimento das pandemias, o presente trabalho apresenta uma sequência didática com atividades que podem ser exploradas nesse momento de isolamento social. Nos conceitos da interdisciplinaridade e ensino online, se buscou a possibilidade de superar a fragmentação do ensino que comumente ocorre tanto no ensino básico como no superior mesmo diante de contextos de normalidade. E, ainda que remotamente, com o auxílio de recursos digitais e a interação em ambientes virtuais, promover o diálogo entre as disciplinas do currículo e a realidade da comunidade escolar, e, nesse caso, uma realidade mundial.

\section{REFERÊNCIAS}

BERBEL, N. A. N. A problematização e a aprendizagem baseada em problemas: diferentes termos ou diferentes caminhos? Interface - Comunicação, Saúde, Educação, v. 2, n. 2, p. 139-154, 1998.

Recebido em: 05/11/2021

Aceite em: 26/08/2021 
BERBEL, N. A. N. Metodologia da Problematização: respostas de lições extraídas da prática Interface - Semina: Ciências Sociais e Humanas, Londrina, v. 35, n. 2, p. 61-76, 2014.

BRASIL. Ministério da Educação. Parâmetros Curriculares Nacionais para o Ensino Médio (PCNEM). 2000. Disponível em: http://portal.mec.gov.br/seb/arquivos/pdf/blegais.pdf

. Ministério da Educação. Base Nacional Comum Curricular. 3. ed. dez. 2018.

Disponível em: <

http://basenacionalcomum.mec.gov.br/images/historico/BNCC_EnsinoMedio_embaixa_site_ 110518.pdf >. Acesso em 08 jul 2020.

. Ministério da Educação. Parecer do Conselho Nacional de Educação (CNE) $n^{\circ}$

5. 2020. Disponível em: pcp005_20 (mec.gov.br). Acesso em 18 jul 2020.

DAVIS, Mike. O monstro bate à nossa parte: a ameaça global da gripe aviária. Rio de Janeiro: Record, 2006.

FARIA, S. B. S. C. et al. Conhecimentos Prévios Sobre Meios Digitais e Desempenho no Ensino Remoto Durante a Pandemia COVID-19. EaD em Foco, v. 10, n. 3, e1229, 2020.

FAZENDA, I. (org.) O que é interdisciplinaridade. São Paulo: Cortez, 2008.

FREIRE, Paulo. Pedagogia da autonomia: saberes necessários à prática educativa. São Paulo: Paz e Terra, 1996. (coleção Leitura).

GERALDI, J. W. Portos de Passagem. 5. ed. São Paulo: Editora WMF Martins Fontes, 2013. (Coleção linguagem)

HOFFMANN, J. Avaliação Mediadora: uma prática em construção da pré-escola à universidade. Porto Alegre: Mediação, 2011.

INEP. Censo Escolar, 2019. Brasília: INEP/Ministério da Educação, 2019.

JOYCE, C. R.; MOREIRA, M. M.; ROCHA, S. S. D. Distance Education or Emergency Remote Educational Activity: in search of the missing link of school education in times of

COVID-19. Research, Society and Development, 9(7): 1-29, e521974299, 2020.

MARASCIULO, Marília. Quanto maior consumo de carne, maior risco de novas pandemias. Revista Galileu. Disponível em:

https://revistagalileu.globo.com/Sociedade/noticia/2020/05/quanto-maior-o-consumo-decarne-maior-o-risco-de-novas-pandemias.html. Acesso em 01 jul.2020.

MOURA, F M. T.; SOUSA, R. F; CARNEIRO, C. C. B. S. O ensino de química contextualizado: as vozes discentes. Revista Insignare Scientia - RIS, v. 1, n. 3, Set./Dez. 2018. 
REIS, A. A.; AZEVEDO, E. C. A. de; FREGUGLIA, J.; RIBEIRO, L. dos S. S. BNCC e as práticas epistêmicas e científicas nos anos finais do ensino fundamental. Revista Insignare Scientia - RIS, v. 4, n. 3, 2021.

SANTOS, Edméa. Educação online para além da EaD: um fenômeno da cibercultura. Actas do X Congresso Internacional Galego-Português de Psicopedagogia. Braga: Universidade do Minho, 2009 ISBN- 978-972-8746-71-1. Disponível em:

http://www.educacion.udc.es/grupos/gipdae/documentos/congreso/xcongreso/pdfs/t12/t12c42 7.pdf. Acesso em 18 jul.2020.

SANTOS, Edméa. EAD, palavra proibida. Educação online, pouca gente sabe o que é. Ensino remoto, o que temos. Notícias, Revista docência e cibercultura, agosto de 2020, online. ISSN 2594-9004. Disponível em: https://www.e-publicacoes.uerj.br/index.php/redoc/announcement/view/1119. Acesso em 18 jul.2020.

SEVERINO, A. J. O conhecimento pedagógico e a interdisciplinaridade: o saber como intencionalização da prática. In Didática e interdisciplinaridade / Ivani CA. Fazenda (org.). — Campinas, SP: Papirus, 1998. 